\title{
Dipstick proteinuria and risk of type 2 diabetes mellitus: a nationwide population-based cohort study
}

\author{
Jimin Jeon and Jinkwon Kim ${ }^{*}$ (D)
}

\begin{abstract}
Background: Proteinuria has been recognized as a marker of systemic inflammation and endothelial dysfunction associated with insulin resistance and $\beta$-cell impairment, which can contribute to the development of type 2 diabetes mellitus (T2DM). However, it is unknown whether the dipstick proteinuria test has a predictive value for new-onset T2DM.

Methods: This retrospective cohort study analyzed 239,287 non-diabetic participants who participated in the Korean nationwide health screening program in 2009-2010. Proteinuria was determined by the urine dipstick test at the baseline health screening. We performed multivariate Cox proportional regression analyses for the development of new-onset T2DM. Follow-up was performed until December 2015.

Results: During the mean follow-up period of 5.73 years, 22,215 participants were diagnosed with new-onset T2DM. The presence of proteinuria was significantly associated with an increased risk of T2DM (adjusted hazard ratio: 1.19, $95 \%$ confidence interval: 1.10, 1.29). There was a positive dose-response relationship between the degree of dipstick proteinuria and T2DM risk. This significant association between proteinuria and T2DM risk was consistent regardless of the fasting glucose level at baseline.
\end{abstract}

Conclusions: Dipstick proteinuria is a significant risk factor for new-onset T2DM. Therefore, proteinuria might be a useful biomarker to identify those at a high risk for developing T2DM.

Keywords: Chronic Kidney Disease, Cohort, Dipstick proteinuria, Type 2 diabetes mellitus

\section{Background}

Type 2 diabetes mellitus (T2DM), a chronic metabolic disorder characterized by hyperglycemia with abnormal glucose regulation, is a major public health concern due to its high prevalence and increasing disease burden [1, 2]. Since T2DM is considered to be largely preventable, developing strategies to prevent T2DM and its complications is an important health topic [3]. For the prevention

*Correspondence: antithrombus@yuhs.ac; antithrombus@gmail.com Department of Neurology, Yongin Severance Hospital, Yonsei University College of Medicine, 363, Dongbaekjukjeon-daero, Giheung-gu,

Yongin 16995, Republic of Korea of T2DM, identifying risk factors and screening at-risk populations are crucial steps [4].

Proteinuria is the presence of excess proteins in the urine and has been primarily recognized as a marker of kidney damage and a predictor of future decline in renal function [5]. Increased inflammatory response and endothelial dysfunction are representative clinical features of proteinuria [6]. The systemic inflammation and endothelial dysfunction are common features of diabetes and are closely related to insulin resistance $[7,8]$. Regarding inflammatory markers and endothelial dysfunction frequently precede the development of T2DM and they are predictive biomarkers for T2DM, we hypothesized that proteinuria may be an independent risk factor for 
new-onset T2DM [9-12]. The urine dipstick test for proteinuria is widely used in clinical practice and public health screenings because of its low cost, ease of use, rapid results, and acceptable accuracy $[13,14]$. There were some prior studies for the association between proteinuria and the development of T2DM [15-17]. However, role of dipstick proteinuria on risk for T2DM is not well-known, and few studies have investigated in Korea. In the current study, we aimed to investigate whether non-diabetic participants with dipstick proteinuria are at an increased risk of new-onset T2DM using a Korean nationwide population-based cohort database.

\section{Methods}

\section{Data source and study design}

Current study had a retrospective cohort design and used data from the National Health Insurance Service-Health Screening Cohort (NHIS-HEALS) in Korea. Information on the dataset has been reported in detail elsewhere [18]. Briefly, the NHIS-HEALS comprises approximately 51 million Korean adults through a random selection of $10 \%$ of all health screening participants aged $40-79$ years. The NHIS-HEALS contains the participants' demographics, health claims data, death statistics, and serial health screening program results. The health screenings were conducted every 2 years between 2002 and 2015 and included a physical examination, lifestyle survey, laboratory tests including fasting serum glucose levels, and dipstick urinalysis for proteinuria. From the health claims data, the participants' diagnoses, made at each hospital, were recorded according to the International Statistical Classification of Diseases and Related Health Problems 10th Revision. Data from the NHIS-HEALS are fully anonymized. The study participants were non-diabetics who underwent a health examination in 2009-2010 (baseline health examination). We excluded participants who had a history of diabetes and those who had no dipstick proteinuria data or covariate data from the baseline health examination. A flow chart of the inclusion process is shown in Fig. 1. From the date of baseline health examination (index date), the participants were followed up until the development of new-onset T2DM (primary outcome), death, loss of eligibility for NHIS due to emigration, or December 2015, whichever occurred earliest. This study was approved by the Institutional Review Board of Yongin Severance Hospital (9-2020-0106), and the need for informed consent was waived due to its retrospective nature and analysis with anonymized data.

\section{Proteinuria and study outcome assessment}

As part of the health screening program, a dipstick urinalysis was performed using urine samples obtained in the morning after overnight fasting. Proteinuria was determined through an interpretation of the dipstick urinalysis results based on a color scale that quantifies proteinuria as 'negative', 'trace $( \pm)$,' ' $1+$ ', ' $2+$ ', ' $3+$ ', or ' $4+$ '. For this study, we classified the dipstick proteinuria results into three groups: 'no proteinuria (-)', 'trace $( \pm)$ ', and 'overt proteinuria $(\geq 1+)$ '. The incidence of primary outcome (new-onset T2DM) was defined as the presence of one of the following two conditions: a health claim code of E11-E14 with the prescription of any anti-diabetic drug (insulin, sulfonylurea, metformin, meglitinide, thiazolidinedione, dipeptidyl peptidase- 4 inhibitor, or $\alpha$-glucosidase inhibitor) during follow-up or a fasting serum glucose level $\geq 126 \mathrm{mg} / \mathrm{dL}$ obtained from the serial health screening program data $[19,20]$.

\section{Covariates}

Demographic and lifestyle characteristics including sex, age, current smoking, alcohol consumption, physical activity, and family history of diabetes were collected from self-reported questionnaires at the health screening. Alcohol consumption was categorized into $<1$ time, 1-2 times, 3-4 times, and $\geq 5$ times based on weekly intake frequencies on average. Physical activity was divided into $<1$ day, 1-4 days, and $\geq 5$ days per week, according to the number of days of exercise on average. The presence of hypertension was determined if participants had a systolic/diastolic blood pressure $\geq 140 / 90 \mathrm{mmHg}$ or answered "yes" in the corresponding health screening questionnaire concerning a diagnosis of hypertension. Body mass index was calculated by dividing the body weight $(\mathrm{kg})$ by the height squared $\left(\mathrm{m}^{2}\right)$, then categorized into underweight $\left(<18.5 \mathrm{~kg} / \mathrm{m}^{2}\right)$, normal $(18.5-23 \mathrm{~kg} /$ $\mathrm{m}^{2}$ ), overweight $\left(23-25 \mathrm{~kg} / \mathrm{m}^{2}\right)$, or obese $\left(\geq 25 \mathrm{~kg} / \mathrm{m}^{2}\right)$ using the body mass index criteria of the World Health Organization for Asians [21]. Estimated glomerular filtration rate was calculated using the Modification of Diet in Renal Disease formula: Estimated glomerular filtration rate $\left(\mathrm{mL} / \mathrm{min} / 1.73 \mathrm{~m}^{2}\right)=186.3 \times($ serum creatinine $\left.{ }^{-1.154}\right) \times\left(\right.$ age $\left.^{-0.203}\right) \times(0.742)$ for women [22] Fasting glucose levels at baseline were divided into two groups: normal fasting glucose $(<100 \mathrm{mg} / \mathrm{dL})$ and impaired fasting glucose $(\geq 100 \mathrm{mg} / \mathrm{dL}$ and $<126 \mathrm{mg} / \mathrm{dL})$, in accordance with the American Diabetes Association criteria [23].

\section{Statistical analyses}

Categorical variables are presented as numbers (\%), and continuous variables are presented as mean (standard deviation). Differences between groups were compared using the Mantel-Haenszel test for linear trend for categorical variables and the Jonckheere's trend test for continuous variables. We illustrated Kaplan-Meier curves for event-free survival for T2DM development according 


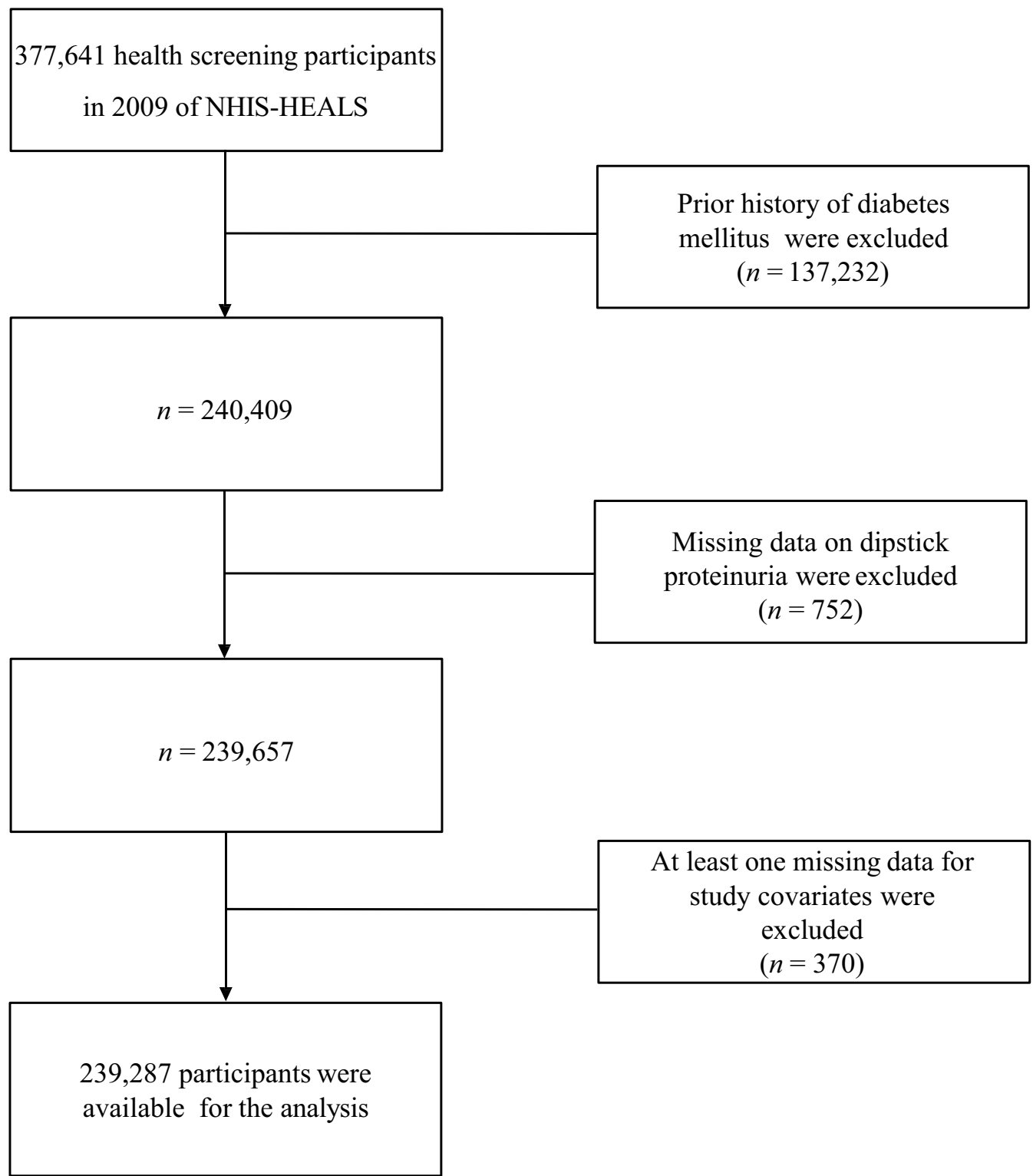

Fig. 1 Flowchart of Included participants. NHIS-HEALS, the National Health Insurance Service-Health Screening Cohort

to dipstick proteinuria, which were compared using a log-rank test. Cox proportional hazard regression analysis was performed to estimate the hazard ratio (HR) and 95\% confidence interval (CI) for the risk of T2DM. In the multivariate Cox models, adjustments were made for sex, age, current smoking, physical activity, alcohol consumption, family history of diabetes, body mass index, systolic blood pressure, fasting glucose level, and estimated glomerular filtration rate at baseline. The SAS version 9.4 (SAS Inc., Cary, NC, USA) and R software version 3.3.3 (The $\mathrm{R}$ Foundation for Statistical Computing, Vienna, Austria; http://www.R-project.org/) were used to manipulate the data and perform all statistical analyses. The statistically significant level for all tests was defined as two-sided $P<0.05$.

\section{Results}

\section{Baseline characteristics}

In accordance with the inclusion and exclusion criteria (Fig. 1), 239,287 participants were included in the study. The baseline characteristics of the participants according to degree of proteinuria are shown in Table 1. Among the 239,287 participants, $95.9 \%(n=229,426)$ did not have proteinuria, $2.1 \%(\mathrm{n}=5,054)$ had trace proteinuria $( \pm)$, 
Table 1 Baseline characteristics of participants according to degree of proteinuria

\begin{tabular}{|c|c|c|c|c|c|}
\hline \multirow[t]{2}{*}{ Variable } & \multirow[t]{2}{*}{ Total } & \multicolumn{3}{|c|}{ Degree of proteinuria } & \multirow[t]{2}{*}{$P$ for trend ${ }^{\dagger}$} \\
\hline & & No proteinuria & Trace proteinuria $( \pm)$ & Overt proteinuria $(\geq 1+)$ & \\
\hline N & 239,287 & 229,426 & 5054 & 4807 & \\
\hline Sex, male & $128,780(53.82)$ & $123,210(53.70)$ & $2881(57.00)$ & $2689(55.94)$ & $<0.001$ \\
\hline Age, years & $57.12 \pm 8.33$ & $57.09 \pm 8.31$ & $57.10 \pm 8.68$ & $58.50 \pm 9.05$ & $<0.001$ \\
\hline Current smoking & $42,824(17.90)$ & $40,863(17.81)$ & $1014(20.06)$ & $947(19.70)$ & $<0.001$ \\
\hline Alcohol consumption, frequency per week & & & & & $<0.001$ \\
\hline$<1$ time & $141,913(59.13)$ & $136,296(59.41)$ & $2811(55.62)$ & $2806(58.37)$ & \\
\hline $1-2$ times & $64,760(27.06)$ & $62,011(27.03)$ & $1511(29.90)$ & $1238(25.75)$ & \\
\hline 3-4 times & $21,364(8.93)$ & $20,418(8.90)$ & $491(9.72)$ & $455(9.47)$ & \\
\hline$\geq 5$ times & $11,250(4.70)$ & $10,701(4.66)$ & $241(4.77)$ & $308(6.41)$ & \\
\hline Exercise, days per week & & & & & 0.398 \\
\hline$<1$ day & $59,871(25.02)$ & $57,433(25.03)$ & $1149(22.73)$ & $1289(26.82)$ & \\
\hline $1-4$ days & $108,348(45.28)$ & $103,860(45.27)$ & $2353(46.56)$ & $2135(44.41)$ & \\
\hline$\geq 5$ days & $71,068(29.70)$ & $68,133(29.70)$ & $1552(30.71)$ & $1383(28.77)$ & \\
\hline Body mass index & & & & & $<0.001$ \\
\hline Underweight $\left(<18.5 \mathrm{~kg} / \mathrm{m}^{2}\right)$ & $5548(2.32)$ & $5280(2.30)$ & $129(2.55)$ & $139(2.89)$ & \\
\hline Normal range $\left(18.5-23 \mathrm{~kg} / \mathrm{m}^{2}\right)$ & $90,072(37.64)$ & $86,733(37.80)$ & $1782(35.26)$ & $1577(32.39)$ & \\
\hline Overweight $\left(23-25 \mathrm{~kg} / \mathrm{m}^{2}\right)$ & $67,809(28.34)$ & $65,153(28.40)$ & $1435(28.39)$ & $1221(25.40)$ & \\
\hline Obese $\left(\geq 25 \mathrm{~kg} / \mathrm{m}^{2}\right)$ & $75,858(31.70)$ & $72,260(31.50)$ & $1708(33.80)$ & $1890(39.32)$ & \\
\hline Hypertension & $128,316(53.62)$ & $122,251(53.29)$ & $2906(57.50)$ & $3159(65.72)$ & $<0.001$ \\
\hline Systolic blood pressure, $\mathrm{mmHg}$ & $124.27 \pm 15.12$ & $124.17 \pm 15.04$ & $125.25 \pm 15.89$ & $128.34 \pm 17.41$ & $<0.001$ \\
\hline Family history of diabetes, yes & $17,836(7.45)$ & $17,060(7.44)$ & $434(8.59)$ & $342(7.11)$ & 0.539 \\
\hline \multicolumn{6}{|l|}{ Laboratory findings } \\
\hline Fasting glucose, mg/dL & $94.13 \pm 11.20$ & $94.07 \pm 11.17$ & $95.05 \pm 11.48$ & $95.91 \pm 11.91$ & $<0.001$ \\
\hline $\begin{array}{l}\text { Estimated glomerular filtration rate, } \mathrm{mL} / \\
\mathrm{min} / 1.73 \mathrm{~m}^{2}\end{array}$ & $83.66 \pm 34.40$ & $83.87 \pm 34.43$ & $79.60 \pm 36.53$ & $77.92 \pm 29.18$ & $<0.001$ \\
\hline
\end{tabular}

Data are represented as the number of participants (\%) or mean \pm standard deviation. ${ }^{\dagger} P$ for trends are derived from the Mantel-Haenszel test for linear trend and the Jonckheere's trend test

and $2.0 \%(\mathrm{n}=4,807)$ had overt proteinuria $(\geq 1+)$. The degree of proteinuria was positively associated with sex, current smoking, alcohol consumption, and obesity. A significantly increasing and decreasing trend according to the degree of proteinuria was observed for the level of systolic blood pressure, fasting glucose and estimated glomerular filtration rate at baseline, respectively.

\section{Risk of T2DM according to proteinuria}

During the mean follow-up period of 5.73 (standard deviation, 1.18) years, 22,215 participants had newonset T2DM. A Kaplan-Meier curve for the cumulative risk of new-onset T2DM showed an increased risk for T2DM according to the presence and degree of proteinuria (Fig. 2). In the univariate Cox regression models, the risk of new-onset T2DM was significantly higher in the overt proteinuria group than in the group without proteinuria (crude HR: 1.50; 95\% CI: 1.38, 1.62). This positive association with proteinuria was maintained in the fully adjusted model (adjusted HR: 1.19; 95\% CI: 1.10, 1.29) (Table 2).

\section{Risk of T2DM according to proteinuria and fasting glucose level}

To investigate whether the association between proteinuria and new-onset T2DM risk differed according to risk factors, subgroup analyses were performed (Additional file 1: Fig. S1). In sex, age, and other subgroups, significant interaction effects with proteinuria for T2DM risk were nor found $(P>0.05)$. To further evaluate whether there were interaction effects between proteinuria and baseline fasting glucose levels, we classified participants according to their baseline fasting glucose levels into the normal fasting glucose group $(<100 \mathrm{mg} / \mathrm{dL})$ and the impaired fasting glucose group $(\geq 100 \mathrm{mg} / \mathrm{dL}$ and $<126 \mathrm{mg} / \mathrm{dL}$ ). In both groups, overt proteinuria was significantly associated with increased risk for new-onset T2DM compared with no proteinuria (Additional file 2: Table S1). 


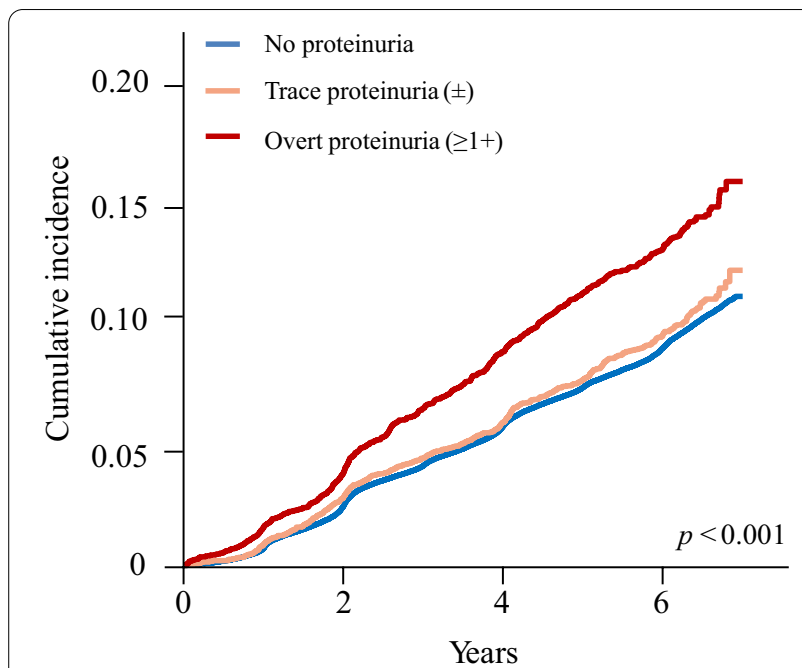

Number at risk

$\begin{array}{rrrr}-229426 & 222088 & 212713 & 127990 \\ -\quad 5054 & 4871 & 4679 & 2813 \\ -\quad 4807 & 4544 & 4236 & 2565\end{array}$

Fig. 2 Kaplan Meier curves for the Event Free Survival for Development of Type 2 Diabetes Mellitus according to Dipstick Proteinuria. $P$ value is derived by a log-rank test

Risk of T2DM according to the change in proteinuria status We further analyzed the risk for new-onset T2DM according to the change in proteinuria status. For this analysis, we collected data on participants who also underwent a health examination between 2002 and 2003 that included a dipstick proteinuria test $(n=238,679)$. The participants were divided into four groups according to the change in proteinuria: Negative/Trace $\rightarrow$ Negative/Trace $(-\rightarrow-$; Group 1), Negative/Trace $\rightarrow \geq 1+(-\rightarrow+$;
Group 2), $\geq 1+\rightarrow$ Negative/Trace $\quad(+\rightarrow-$; Group $3), \geq 1+\rightarrow \geq 1+(+\rightarrow+$; Group 4). In the analyses, group $1(-\rightarrow-)$ had lower risk for new-onset T2DM compared with the other three groups (Table 3). Change in lifestyle characteristics (smoking status, physical activity, alcohol consumption) of study participants according to change in proteinuria status are shown in Additional file 3: Table S2.

\section{Discussion}

This cohort study investigated the association between dipstick proteinuria and the risk of new-onset T2DM using the nationwide population-based health screening database in Korea. Participants with proteinuria had a higher risk of developing T2DM independent of other risk factors, including fasting glucose level. There was a dose-dependent increase in the risk of T2DM according to the degree of dipstick proteinuria. The urine dipstick test is already a widely used screening tool for proteinuria and other urinary issues [24]. Our study implies that the dipstick proteinuria test may also be useful for identifying patients at high risk of developing T2DM.

There are several potential mechanisms that may help explain the relationship between proteinuria and increased T2DM risk. The first is that proteinuria is a sensitive marker of inflammation, and sustained proteinuria is considered a cause of further inflammation and oxidative stress $[25,26]$. Numerous studies have documented a strong positive relationship between proteinuria and inflammatory biomarkers such as C-reactive protein, TNF- $\alpha$, interleukin-6, and monocyte chemotactic protein-1 [27, 28]. In a large cohort of chronic kidney disease patients, the inflammation score was positively associated with proteinuria, regardless of estimated glomerular filtration rate [29]. Recent evidence has suggested that proteinuria itself and underlying medical conditions can elicit pro-inflammatory effects and the secretion of inflammatory cytokines including monocyte

Table 2 Risk of new-onset type 2 diabetes mellitus according to degree of proteinuria

\begin{tabular}{|c|c|c|c|c|c|}
\hline \multirow[t]{2}{*}{ Degree of proteinuria } & \multirow[t]{2}{*}{ Case $^{a}$} & \multicolumn{4}{|l|}{$\mathrm{HR}(95 \% \mathrm{Cl})$} \\
\hline & & Crude model & Model 1 & Model 2 & Model 3 \\
\hline No proteinuria & 21,086 & 1 (Ref) & 1 (Ref) & 1 (Ref) & 1 (Ref) \\
\hline Trace proteinuria $( \pm)$ & 491 & $1.06[0.97-1.16]$ & $1.04[0.95-1.14]$ & $1.01[0.92-1.10]$ & $0.96[0.88-1.05]$ \\
\hline Overt proteinuria $(\geq 1+)$ & 638 & $1.50[1.38-1.62]$ & $1.46[1.35-1.58]$ & $1.32[1.22-1.42]$ & $1.19[1.10-1.29]$ \\
\hline
\end{tabular}

Model 1: adjusted for sex, and age

Model 2: adjusted for sex, age, current smoking, physical activity, alcohol consumption, family history of diabetes, body mass index, and systolic blood pressure Model 3: adjusted for sex, age, current smoking, physical activity, alcohol consumption, family history of diabetes, body mass index, systolic blood pressure, fasting glucose level, and estimated glomerular filtration rate

$H R$ hazard ratio, $\mathrm{Cl}$ indicates confidence interval

${ }^{\text {a }}$ New-onset type 2 diabetes mellitus 
Table 3 Risk of type 2 diabetes mellitus risk according to change in proteinuria status

\begin{tabular}{lllllll}
\hline Change in proteinuria & $\begin{array}{l}\text { Participants } \\
\text { (number) }\end{array}$ & Case $^{\mathbf{a}}$ & & HR (95\% Cl) & & \\
\cline { 5 - 7 } & & & Crude model & Model 1 & Model 2 & Model 3 \\
\hline Negative/Trace $\rightarrow$ Negative/Trace & 231,223 & 21,249 & 1 (Ref) & 1 (Ref) & 1 (Ref) & 1 (Ref) \\
Negative/Trace $\rightarrow \geq 1+$ & 4380 & 569 & $1.46[1.35-1.59]$ & $1.44[1.32-1.56]$ & $1.30[1.19-1.41]$ & $1.18[1.08-1.28]$ \\
$\geq 1+\rightarrow$ Negative/Trace & 2660 & 276 & $1.15[1.02-1.29]$ & $1.19[1.05-1.33]$ & $1.12[0.99-1.26]$ & $1.13[1.01-1.28]$ \\
$\geq 1+\rightarrow \geq 1+$ & 416 & 68 & $1.88[1.48-2.39]$ & $1.77[1.40-2.25]$ & $1.53[1.20-1.94]$ & $1.39[1.10-1.76]$ \\
\hline
\end{tabular}

Model 1: adjusted for sex and age

Model 2: adjusted for sex, age, current smoking, physical activity, alcohol consumption, family history of diabetes, body mass index, systolic blood pressure

Model 3: adjusted for sex, age, current smoking, physical activity, alcohol consumption, family history of diabetes, body mass index, systolic blood pressure, fasting glucose level, and estimated glomerular filtration rate

$H R$ hazard ratio, $\mathrm{Cl}$ indicates confidence interval

${ }^{\text {a }}$ New-onset type 2 diabetes mellitus

chemotactic protein-1, endothelin-1, and nuclear factor${ }_{k} B[30,31]$. Secretion of these chemokines and inflammatory cytokines has been shown to induce insulin resistance, a major hallmark of T2DM pathogenesis [32-34]. That is to say, elevated levels of the inflammatory biomarkers are predictors of the development of T2DM $[35,36]$. The implications of systemic inflammation and proteinuria may explain the high risk of T2DM in patients with proteinuria.

Microvascular endothelial dysfunction is a typical clinical feature found in patients with proteinuria [36, 37]. $\beta$-cells of the pancreatic islets secrete insulin and play a major role in glycemic control and the development of diabetes [38]. The pancreatic islet is highly vassalized with an extensive capillary network, which is essential for the survival and function of islet $\beta$-cells [39]. The islet endothelial dysfunction contributes to impaired $\beta$-cell function in diabetes [40]. Furthermore, impaired endothelial permeability disrupts insulin delivery to the skeletal muscle, liver, or adipose tissue, thereby limiting insulin action [41]. Many epidemiological studies have reported that biomarkers of endothelial dysfunction could be predictors of T2DM development [9, 42]. Although it is uncertain whether endothelial dysfunction is a consequence or preceding factor of T2DM [12], the link between endothelial dysfunction and diabetes may explain the increased risk of T2DM in patients with proteinuria, the result of current study.

The kidneys play a central role in glucose homeostasis, and impaired renal proximal tubules may be another contributing factor in the development of T2DM in patients with proteinuria [43]. The kidneys filter approximately $180 \mathrm{~g}$ of glucose per day, and glucose reabsorption in the kidney is primarily mediated by sodium glucose cotransporters 1 and 2 in the proximal tubule, which help regulate blood glucose levels [44]. The proximal tubule is also a major site of albumin reabsorption in the kidneys [45].
Damaged proximal tubules, leading to the presence of proteinuria, may interfere with the reabsorption of glucose and regulation of glucose homeostasis.

Due to the limitation of the observational design without interventions, we could not conclude whether proteinuria had a causal effect on the risk of T2DM (mediator) or that proteinuria only reflected an underlying inflammatory or other deteriorating condition associated with an increased risk of T2DM (risk marker). However, substantial clinical and experimental evidence has suggested that systemic inflammation and endothelial dysfunction can contribute to the pathogenesis and development of T2DM, suggesting they are risk factors for diabetes $[10,46]$. Therefore, we supposed that proteinuria may be a potential treatment target for reducing the development of T2DM and improving glycemic control. The findings of the current study, namely, the dose-response increase in T2DM risk according to the degree of proteinuria and the concurrent change in the risk according to the change in proteinuria, suggest that proteinuria reduction would have a beneficial effect on the prevention of diabetes. Intense exercise, heat waves and extreme temperatures, and consumption of dietary protein in excess of recommended amounts accelerate a progressive loss of renal capacity leading to proteinuria [47-49]. However, we could not consider these variable due to unavailability of such information from the healthinsurance database. In addition, modifications in lifestyle factors, anti-proteinuric therapies and anti-hypertensive therapies such as angiotensin-converting enzyme inhibitors or angiotensin receptor blockers have been reported to have an additive effect on the reduction of proteinuria [50-52]. Thus, further research is needed to evaluate the effect of these interventions on reducing proteinuria to aid in the prevention of T2DM.

We should acknowledge several limitations of current study. First, current study had a retrospective 
observational design without interventions; it was therefore difficult to explain the exact mechanism between proteinuria and the risk for new-onset T2DM. Second, urine dipstick proteinuria was assessed by a single measurement, which may have a measurement error. Third, as our study's participants were limited to the Korean population, the results should be interpreted with caution. Nonetheless, this study was strengthened by its use of large-scale reliable data from the NHIS, representing nationwide health information on the Korean population, and its evaluation of the long-term risk for new-onset T2DM through both health claims data and serially performed health screening examinations.

\section{Conclusions}

In conclusion, the present study found that dipstick proteinuria was an independent risk factor for the development of new-onset T2DM. The risk of T2DM increased proportionally with the severity of dipstick proteinuria. Further large-scale clinical and experimental studies should be conducted to investigate the exact mechanisms between of them and to determine whether proteinuria is a potential treatment target for the prevention and control of T2DM.

\section{Abbreviations \\ T2DM: Type 2 diabetes mellitus; NHIS-HEALS: National Health Insurance Service-Health Screening Cohort; HR: Hazard ratio; Cl: Confidence interval.}

\section{Supplementary Information}

The online version contains supplementary material available at https://doi. org/10.1186/s12967-021-02934-y.

Additional file 1: Fig. S1. Effect of proteinuria on type 2 diabetes mellitus in each subgroup by risk factor.

Additional file 2: Table S1. Effect of proteinuria on type 2 diabetes mellitus according to the baseline fasting glucose level.

Additional file 3: Table S2. Change in lifestyle characteristics of study participants according to change in proteinuria status.

\section{Acknowledgements}

This study used the NHIS-HEALS dataset (NHIS-2018-2-236) created by the National Health Insurance Sharing Service.

\section{Authors' contributions}

$J J$ and JK conceived and designed the study. JJ analyzed the data and drafted the manuscript. JK acquired the data, drafted the manuscript, and provided critical revision of the manuscript. All authors have critically interpreted the results and have read and approved the final manuscript. All authors read and approved the final manuscript.

\section{Funding}

This work was supported by the Basic Science Research Program through the National Research Foundation of Korea funded by the Ministry of Education (NRF-2020R111A1A01060447).

\section{Availability of data and materials}

The dataset (NHIS-HEALS) supporting the conclusion of this study is available from the National Health Insurance Sharing Service (http://nhiss.nhis.or.kr/bd/ ab/bdaba021eng.do). To gain access to the dataset, a completed application form, research proposal, and an applicant's approval document from the institutional review board should be submitted to and reviewed by the inquiry committee of research support in National Health Insurance Sharing Service.

\section{Declarations}

\section{Ethics approval and consent to participate}

The NHIS-HEALS data were fully anonymized for privacy protection. Due to the retrospective nature and use of de-identified data, the current study was approved with waiver of the requirement to obtain informed consent by the Institutional Review Board of the Yongin Severance Hospital (9-2020-0106). The study was performed in accordance with approved guidelines and regulations for medical research expressed in the Declaration of Helsinki.

\section{Consent for publication}

Not applicable.

\section{Competing interests}

The authors declare that they have no competing interests.

Received: 31 March 2021 Accepted: 9 June 2021

Published online: 26 June 2021

\section{References}

1. Ashcroft FM, Rorsman P. Diabetes mellitus and the $\beta$ cell: the last ten years. Cell. 2012;148:1160-71.

2. Cho NH, Shaw JE, Karuranga S, Huang Y, da Rocha Fernandes JD, Ohlrogge AW, et al. IDF Diabetes Atlas: Global estimates of diabetes prevalence for 2017 and projections for 2045. Diabetes Res Clin Pract. 2018;138:271-81.

3. Hu FB. Globalization of diabetes: the role of diet, lifestyle, and genes. Diabetes Care. 2011;34:1249-57.

4. Petrie JR, GuzikTJ, Touyz RM. Diabetes, hypertension, and cardiovascular disease: clinical insights and vascular mechanisms. Can J Cardiol. 2018;34:575-84.

5. Cravedi P, Remuzzi G. Pathophysiology of proteinuria and its value as an outcome measure in chronic kidney disease. $\mathrm{Br} J$ Clin Pharmacol. 2013;76:516-23.

6. Pedrinelli R, Dell'Omo G, Penno G, Mariani M. Non-diabetic microalbuminuria, endothelial dysfunction and cardiovascular disease. Vasc Med. 2001;6:257-64

7. Ruotsalainen E, Vauhkonen I, Salmenniemi U, Pihlajamaki J, Punnonen K, Kainulainen S, et al. Markers of endothelial dysfunction and low-grade inflammation are associated in the offspring of type 2 diabetic subjects. Atherosclerosis. 2008;197:271-7.

8. Caballero AE. Endothelial dysfunction, inflammation, and insulin resistance: a focus on subjects at risk for type 2 diabetes. Curr Diab Rep. 2004:4:237-46.

9. Meigs JB, Hu FB, Rifai N, Manson JE. Biomarkers of endothelial dysfunction and risk of type 2 diabetes mellitus. JAMA. 2004;291:1978-86.

10. Qiu S, Cai X, Liu J, Yang B, Zügel M, Steinacker JM, et al. Association between circulating cell adhesion molecules and risk of type 2 diabetes: A meta-analysis. Atherosclerosis. 2019;287:147-54.

11. Song Y, Manson JE, Tinker L, Rifai N, Cook NR, Hu FB, et al. Circulating levels of endothelial adhesion molecules and risk of diabetes in an ethnically diverse cohort of women. Diabetes. 2007:56:1898-904.

12. Hahad O, Wild PS, Prochaska JH, Schulz A, Hermanns I, Lackner KJ, et al. Endothelial function assessed by digital volume plethysmography predicts the development and progression of Type 2 diabetes mellitus. J Am Heart Assoc. 2019:8:e012509.

13. Lim WH, Choi EK, Han KD, Rhee TM, Lee HJ, Lee SR, et al. Proteinuria detected by urine dipstick test as a risk factor for atrial fibrillation: a nationwide population-based study. Sci Rep. 2017;7:6324. 
14. Lim D, Lee DY, Cho SH, Kim OZ, Cho SW, An SK, et al. Diagnostic accuracy of urine dipstick for proteinuria in older outpatients. Kidney Res Clin Pract. 2014;33:199-203.

15. Muris DM, Houben AJ, Schram MT, Stehouwer CD. Microvascular dysfunction is associated with a higher incidence of type 2 diabetes mellitus: a systematic review and meta-analysis. Arterioscler Thromb Vasc Biol. 2012;32:3082-94.

16. Ishizaka Y, Yamakado M, Toda A, Tani M, Ishizaka N. Relationship between serum uric acid and serum oxidative stress markers in the Japanese general population. Nephron Clin Pract. 2014;128:49-56.

17. Saadi MM, Roy MN, Haque R, Tania FA, Mahmood S, Ali N. Association of microalbuminuria with metabolic syndrome: a cross-sectional study in Bangladesh. BMC Endocr Disord. 2020;20:153.

18. Seong SC, Kim YY, Park SK, Khang YH, Kim HC, Park JH, et al. Cohort profile: the National Health Insurance Service-National Health Screening Cohort (NHIS-HEALS) in Korea. BMJ Open. 2017;7:e016640.

19. Kim YS, Han YE, Choi EA, You NY, Lee JW, You HS, et al. Statin use increased new-onset diabetes in hypercholesterolemic individuals: Data from the Korean National Health Insurance Service-National Health Screening Cohort database (NHIS-HEALS). Prim Care Diab. 2020;14:246-53.

20. Kim J, Hyun HJ, Choi EA, Yoo JW, Lee S, Jeong N, et al. Diabetes, metformin, and lung cancer: retrospective study of the Korean NHIS-HEALS Database. Clin Lung Cancer. 2020;21:e551-9.

21. World Health Organization. The Asia-Pacific perspective: redefining obesity and its treatment. Sydney: Health Communications; 2000.

22. Levey AS, Bosch JP, Lewis JB, Greene T, Rogers N, Roth D. A more accurate method to estimate glomerular filtration rate from serum creatinine: a new prediction equation. Modification of Diet in Renal Disease Study Group. Ann Intern Med. 1999;130:461-70.

23. American Diabetes Association. Diagnosis and classification of diabetes mellitus. Diab Care. 2014;37(Suppl 1):S81-90.

24. Waisman Y, Zerem E, Amir L, Mimouni M. The validity of the uriscreen test for early detection of urinary tract infection in children. Pediatrics. 1999;104:41.

25. Toblli JE, Bevione P, Di Gennaro F, Madalena L, Cao G, Angerosa M. Understanding the mechanisms of proteinuria: therapeutic implications. Int J Nephrol. 2012;2012:546039.

26. Trimarchi $H$, Muryan $A$, Dicugno $M$, Young $P$, Forrester $M$, Lombi F, et al. Proteinuria: an ignored marker of inflammation and cardiovascular disease in chronic hemodialysis. Int J Nephrol Renovasc Dis. 2012;5:1-7.

27. Kshirsagar AV, Bomback AS, Bang H, Gerber LM, Vupputuri S, Shoham DA, et al. Association of C-reactive protein and microalbuminuria (from the National Health and Nutrition Examination Surveys, 1999 to 2004). Am J Cardiol. 2008;101:401-6.

28. Upadhyay A, Larson MG, Guo CY, Vasan RS, Lipinska I, O'Donnell CJ, et al. Inflammation, kidney function and albuminuria in the Framingham Offspring cohort. Nephrol Dial Transplant. 2011;26:920-6.

29. Gupta J, Mitra N, Kanetsky PA, Devaney J, Wing MR, Reilly M, et al. Association between albuminuria, kidney function, and inflammatory biomarker profile in CKD in CRIC. Clin J Am Soc Nephrol. 2012;7:1938-46.

30. Tryggvason K, Pettersson E. Causes and consequences of proteinuria: the kidney filtration barrier and progressive renal failure. J Intern Med. 2003;254:216-24.

31. Eddy AA. Proteinuria and interstitial injury. Nephrol Dial Transplant. 2004;19:277-81.

32. Imai Y, Dobrian AD, Weaver JR, Butcher MJ, Cole BK, Galkina EV, et al. Interaction between cytokines and inflammatory cells in islet dysfunction, insulin resistance and vascular disease. Diabetes Obes Metab. 2013;15(Suppl 3):117-29.

33. Wilkes JJ, Hevener A, Olefsky J. Chronic endothelin-1 treatment leads to insulin resistance in vivo. Diabetes. 2003;52:1904-9.

34. Wong E, Freiberg M, Tracy R, Kuller L. Epidemiology of cytokines: the Women On the Move through Activity and Nutrition (WOMAN) Study. Am J Epidemiol. 2008;168:443-53.

35. Wang X, Bao W, Liu J, Ouyang YY, Wang D, Rong S, et al. Inflammatory markers and risk of type 2 diabetes: a systematic review and meta-analysis. Diabetes Care. 2013;36:166-75.
36. Martens RJH, Houben A, Kooman JP, Berendschot T, Dagnelie PC, van der Kallen $\mathrm{CJH}$, et al. Microvascular endothelial dysfunction is associated with albuminuria: the Maastricht Study. J Hypertens. 2018;36:1178-87.

37. Joles JA, Stroes ES, Rabelink TJ. Endothelial function in proteinuric renal disease. Kidney Int Suppl. 1999;71:S57-61.

38. Gastaldelli A. Role of beta-cell dysfunction, ectopic fat accumulation and insulin resistance in the pathogenesis of type 2 diabetes mellitus. Diabetes Res Clin Pract. 2011;93(Suppl 1):S60-5.

39. Zanone MM, Favaro E, Camussi G. From endothelial to beta cells: insights into pancreatic islet microendothelium. Curr Diab Rev. 2008:4:1-9.

40. Hogan MF, Hull RL. The islet endothelial cell: a novel contributor to beta cell secretory dysfunction in diabetes. Diabetologia. 2017;60:952-9.

41. Barrett EJ, Eggleston EM, Inyard AC, Wang H, Li G, Chai W, et al. The vascular actions of insulin control its delivery to muscle and regulate the rate-limiting step in skeletal muscle insulin action. Diabetologia. 2009:52:752-64.

42. Thorand B, Baumert J, Chambless L, Meisinger C, Kolb H, Döring A, et al. Elevated markers of endothelial dysfunction predict type 2 diabetes mellitus in middle-aged men and women from the general population. Arterioscler Thromb Vasc Biol. 2006;26:398-405.

43. Mitrakou A. Kidney: its impact on glucose homeostasis and hormonal regulation. Diab Res Clin Pract. 2011;93(Suppl 1):S66-72.

44. DeFronzo RA, Davidson JA, Del Prato S. The role of the kidneys in glucose homeostasis: a new path towards normalizing glycaemia. Diabetes Obes Metab. 2012;14:5-14

45. Lazzara MJ, Deen WM. Model of albumin reabsorption in the proximal tubule. Am J Physiol Renal Physiol. 2007;292:F430-9.

46. Pinkney JH, Stehouwer CD, Coppack SW, Yudkin JS. Endothelial dysfunction: cause of the insulin resistance syndrome. Diabetes. 1997;46(Suppl 2):S9-13.

47. de Lorenzo A, Liaño F. High temperatures and nephrology: The climate change problem. Nefrologia. 2017;37:492-500.

48. Fan CH, Lin SC, Tsai KZ, Wu TJ, Lin YP, Lin YK, et al. Association of Single Measurement of dipstick proteinuria with physical performance of military males: the CHIEF study. BMC Nephrol. 2020;21:287.

49. Luyckx VA, Mardigan TA. High protein diets may be hazardous for the kidneys. Nephrol Dial Transplant. 2004;19:2678-9.

50. Kunz R, Friedrich C, Wolbers M, Mann JF. Meta-analysis: effect of monotherapy and combination therapy with inhibitors of the renin angiotensin system on proteinuria in renal disease. Ann Intern Med. 2008;148:30-48.

51. Wilmer WA, Rovin BH, Hebert CJ, Rao SV, Kumor K, Hebert LA. Management of glomerular proteinuria: a commentary. J Am Soc Nephrol. 2003;14:3217-32.

52. Wakasugi M, Kazama J, Narita I, Iseki K, Fujimoto S, Moriyama T, et al. Association between overall lifestyle changes and the incidence of proteinuria: a population-based. Cohort Study Intern Med. 2017;56:1475-84.

\section{Publisher's Note}

Springer Nature remains neutral with regard to jurisdictional claims in published maps and institutional affiliations.

Ready to submit your research? Choose BMC and benefit from:

- fast, convenient online submission

- thorough peer review by experienced researchers in your field

- rapid publication on acceptance

- support for research data, including large and complex data types

- gold Open Access which fosters wider collaboration and increased citations

- maximum visibility for your research: over 100M website views per year

At BMC, research is always in progress.

Learn more biomedcentral.com/submissions 